WellBeing International

WBI Studies Repository

$10-2008$

\title{
Visual Attention and its Relation to Knowledge States in Chimpanzees, Pan troglodytes
}

\author{
Megan J. Bulloch \\ The Ohio State University \\ Sarah T. Boysen \\ The Ohio State University \\ Ellen E. Furlong \\ The Ohio State University
}

Follow this and additional works at: https://www.wellbeingintlstudiesrepository.org/acwp_asie

Part of the Animal Studies Commons, Comparative Psychology Commons, and the Other Animal Sciences Commons

\section{Recommended Citation}

Bulloch, M. J., Boysen, S. T., \& Furlong, E. E. (2008). Visual attention and its relation to knowledge states in chimpanzees, Pan troglodytes. Animal Behaviour, 76(4), 1147-1155.

This material is brought to you for free and open access by WellBeing International. It has been accepted for inclusion by an authorized administrator of the WBI Studies Repository. For more information, please contact wbisr-info@wellbeingintl.org.

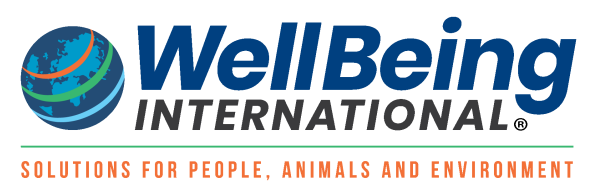




\title{
Visual Attention and its Relation to Knowledge States in Chimpanzees, Pan troglodytes
}

\author{
Megan J. Bulloch, Sarah T. Boysen, and Ellen E. Furlong \\ Ohio State University
}

\section{$\underline{\text { KEYWORDS }}$}

attention, chimpanzee, comparative cognition, eye gaze, gaze-following, Pan troglodytes, perspectivetaking, Theory of Mind, visual attention

\section{$\underline{\text { ABSTRACT }}$}

Primates rely on visual attention to gather knowledge about their environment. The ability to recognize such knowledge-acquisition activity in another may demonstrate one aspect of Theory of Mind. Using a series of experiments in which chimpanzees were presented with a choice between an experimenter whose visual attention was available and another whose vision was occluded, we asked whether chimpanzees understood the relationship between visual attention and knowledge states. The animals showed sophisticated understanding of attention from the first presentation of each task. Under more complex experimental conditions, the subjects had more difficulty with species-typical processing of attentional cues and those likely to be learned during human contact. We discuss the results with respect to the comparative impact of enculturation on chimpanzees.

Whether the ability to discriminate one's own knowledge state from another's is uniquely human has been at the heart of a lively debate in comparative cognition (e.g. Povinelli \& Eddy 1996a, b; Povinelli 2000; Tomasello 2000; Povinelli et al. 2002; Povinelli \& Vonk 2003, 2004). However, research in the domain of nonhuman primates' understanding of the mind has not produced definitive conclusions about chimpanzees' ability to hold a Theory of Mind (Premack \& Woodruff 1978; Povinelli \& Eddy 1996a, b; Tomasello et al. 1999, 2001, 2003, 2007; Hare et al. 2000, 2001; Povinelli 2000). Reports from Povinelli and colleagues, working with a group of seven adolescent chimpanzees at the New Iberia Primate Research Center, failed to demonstrate this capability (Povinelli \& Eddy 1996a, b; Reaux et al. 1999; Povinelli 2000). The New Iberia chimpanzees learned a stimulus-based rule to solve a preferential gesture task based on visual access to 'face' and 'eyes' (Reaux et al. 1999). Thus, rather than showing global understanding of intentional aspects of attention, the animals learned to respond to what the investigators characterized as 'face' and 'eye' rules. Correct responses on these conditions could be generated using a perceptually bound rule such as, 'Gesture to person with face visible'. Interestingly, these chimpanzees never learned a comparable stimulus rule for eyes ('Gesture to person with eyes visible'). However, according to Povinelli and colleagues (Povinelli et al. 1999; Povinelli 2000), the 
application of a perceptual mechanism based upon the visibility of the experimenter's face, rather than an understanding of the experimenter's intentional state or a mental representation of eyes as a means to acquire knowledge, best explained their chimpanzees' responses to the task.

New evidence suggests that chimpanzees' understanding of another chimpanzee's visual perspective (and hence, acquisition of knowledge) could be different from their own, and might govern subsequent behavior (Tomasello et al. 2003). In a series of innovative experiments, Hare et al. (2001) instigated food competition between dominant and subordinate chimpanzees. When both a dominant animal and a subordinate had visual access to food, the dominant chimpanzee successfully obtained the food reward. In subsequent conditions, when the food was visually available only to the subordinate animal, that chimpanzee was more likely to approach the food reward (Hare et al. 2001). Given the hesitancy of subordinate animals to engage in direct competition with dominant conspecifics during previous experimental conditions, and more generally during daily social interactions, the investigators suggested that these findings could be explained best by invoking a rudimentary Theory of Mind. As such, they proposed that the subordinate chimpanzees understood what the dominant chimp could and could not see, and acted accordingly. This implied an understanding of both behaviour (dominant chimpanzees steal food from subordinates), the intentional aspects of visual attention (the dominant animal could not see the food; therefore, he would not seek it out), and subsequent understanding of mental states (a subordinate animal can approach food because he is aware that the dominant chimpanzee does not know the food is there). Given the reliance of their design on the daily experiences and naturalistic relationships among chimps, that is, food competition, the design may have shown more genuinely the chimpanzees' capacity for Theory of Mind (Hare et al. 2001).

Under captive conditions, much recent work has focused on the visual attention paradigm (e.g. Povinelli \& Eddy 1996a, b; Tomasello et al. 1998; Reaux et al. 1999; Santos \& Hauser 1999; Kaminski et al. 2004; Bräuer et al. 2005; Santos et al. 2006). These experimental designs hint at chimpanzees' understanding of the intentions of others (Leavens et al. 1996; Leavens \& Hopkins 1998; Hare et al. 2001; Hostetter et al. 2007). In particular, a recent report from Hostetter et al. (2007) provided evidence that a large population of chimpanzees $(N=116)$ at Yerkes Primate Research Center, Atlanta, GA, U.S.A., understood that the attentional state of human experimenters was based on eye gaze. These subjects responded to experimenters who were offering food, and either had their eyes closed, their eyes open, a hand over their eyes, or a hand over their mouth. Results indicated that subjects produced more behaviours when the experimenter's eyes were visible than when they were not, and more vocalizations when the experimenter's eyes were closed than when they were open (Hostetter et al. 2007). These findings suggest at least a rudimentary understanding of the value of eyes for knowledge acquisition. However, these findings do not preclude questions concerning the visual attention paradigm. Does success with the visual attention paradigm indicate a rudimentary Theory of Mind, or might there be a more parsimonious account for these results, such as a perceptually bound rule learning mechanism?

Despite our present report, we do not mean to suggest that the visual attention paradigm is the gold standard for showing Theory of Mind in nonhuman animals. Further development of innovative paradigms such as those used by Hare et al. (2001) and others discussed above may provide additional experimental approaches for understanding of chimpanzee cognitive capacities. Nevertheless, we chose to replicate the visual attention paradigm, despite its limitations. Casual observations of our chimpanzees at The Ohio State University, Columbus, OH, U.S.A., suggested numerous examples of behaviour and social interactions that appeared to contradict findings from the Reaux et al. (1999) study. Such anecdotal evidence suggested that the Ohio Stat chimpanzees understood the implications of visual attention, as well as the importance of seeking and maintaining visual attention to achieve a specific goal (often some tasty treat from a caregiver). Although one of the primary limitations of the visual attention paradigm is the 
difficulty in discriminating between various levels of understanding, the replication of a comparable experimental approach with another chimpanzee population would be important to ascertain whether there could be group differences between the two colonies. Finally, in contrast to emerging evidence, results from the visual attention paradigm reported by Povinelli (2000) and Povinelli et al. (1999) have had an impact beyond the current primate cognition literature, because their findings are often presented as a definitive demonstration that 'the chimpanzee' lacks Theory of Mind. These and related findings raise doubts as to whether the cognitive abilities of chimpanzees are merely perceptually bound or based upon associative learning, as suggested by findings from Povinelli and colleagues. To address these questions directly, we replicated the visual attention paradigm with The Ohio State University chimpanzee group.

\section{EXPERIMENT 1}

\section{Methods}

\section{Subjects}

We tested seven chimpanzees housed at the Chimpanzee Cognition Center, Columbus, OH, U.S.A., and ranging in age from 7 to 45 years. These included two adult females (Sarah, 45; Sheba, 23), three adult males (Kermit, 24; Darrell, 24; Bobby, 17), and a juvenile female and male (Ivy and Keeli, both 7 years old). All subjects had participated in previous cognitive studies related to tool use, spatial representation and numerical competence, among others (e.g. Kuhlmeier et al. 1999; Kuhlmeier \& Boysen 2001, 2002; Boysen 2006; Furlong et al. 2008). The animals lived in mixed-age social groups in an enriched environment with 24-h access to outdoor play enclosures equipped with foraging sites and large-scale climbing structures designed to encourage species-specific behavioural activities. Their daily diet included a wide variety of fresh fruits and vegetables fed throughout the day, supplemented with high-protein biscuits included in the evening meal, and water available ad libitum. We used no deprivation procedures at any time during the course of the experiment.

All subjects received 12 baseline trials, modelled after the procedures reported by Reaux et al. (1999). Two experimenters stood on opposite sides of a painted plywood platform $(1.3 \times 0.91 \mathrm{~m})$, each holding a $85 \mathrm{~g}$ cup of yogurt or applesauce. The platform ensured that the distance between the two experimenters was consistent during testing. When the chimps gestured towards an experimenter, their response was readily observable and definitive. We videotaped all trials for offline coding by a student research assistant who was naïve to the experimental hypotheses. Because of structural limitations in the animals' housing areas, we conducted the trials with an individual chimpanzee seated in an overhead transfer chute (interior dimensions $0.6 \times 0.6 \mathrm{~m}, 1.8 \mathrm{~m}$ above the ground) that had a horizontal opening along the bottom ledge through which the animals could point.

Presentation of the trials was counterbalanced by left/right position and experimenter (experimenter 1 or 2 ), with the chimpanzees completing two baseline sessions of six trials each. During baseline trials, the chimpanzees gestured towards the experimenter who presented them immediately with the food reward that she was holding. Following Reaux et al.'s (1999) criteria for pretesting procedures, the chimps completed at least five baseline trials over two consecutive sessions, for a criterion of five of six correct responses (83\%). This ensured that the animals would point towards an experimenter holding the food reward. As noted, all animals readily met criterion on the baseline trials, and moved to experimental testing.

Experiment 1 consisted of 12 sessions, with four baseline and two experimental trials each. We randomized the order of experimental trials by session and condition, Criteria for presentation of the experimental trials followed the methods of Reaux et al. (1999), such that each chimpanzee participated 
in four trials of the six experimental conditions, representing a total of 24 experimental trials per subject. Unlike the baseline trials, experimental trials always included a choice between two experimenters. The six experimental configurations included the following: in condition 1, one experimenter faced forward, and the second faced backwards (Fig. 1a). For condition 2, one experimenter held a white plastic bucket next to her head, at shoulder level, and the second experimenter placed an identical bucket over her head (Fig. 1b). During condition 3, one experimenter held a screen $(33 \times 23 \mathrm{~cm})$ attached to a wooden tongue depressor next to her face and the second held the screen in front, covering her face (Fig. 1c). Under condition 4, one experimenter wore a blindfold placed over her mouth, and the other experimenter had a blindfold over her eyes (Fig. 1d). In condition 5, one experimenter faced forward and the other experimenter gazed away to the side (Fig. 1e). During condition 6, both experimenters faced forward, but one held her eyes open and the other closed her eyes (Fig. 1f).

Figure 1. Experimental conditions for experiment 1: (a) buckets, (b) screens, (c) blindfolds, (d) front/back, (e) gaze away and ( $f$ ) eyes open and closed. The experimenter on the right side in each panel is demonstrating the 'seeing' conditions.

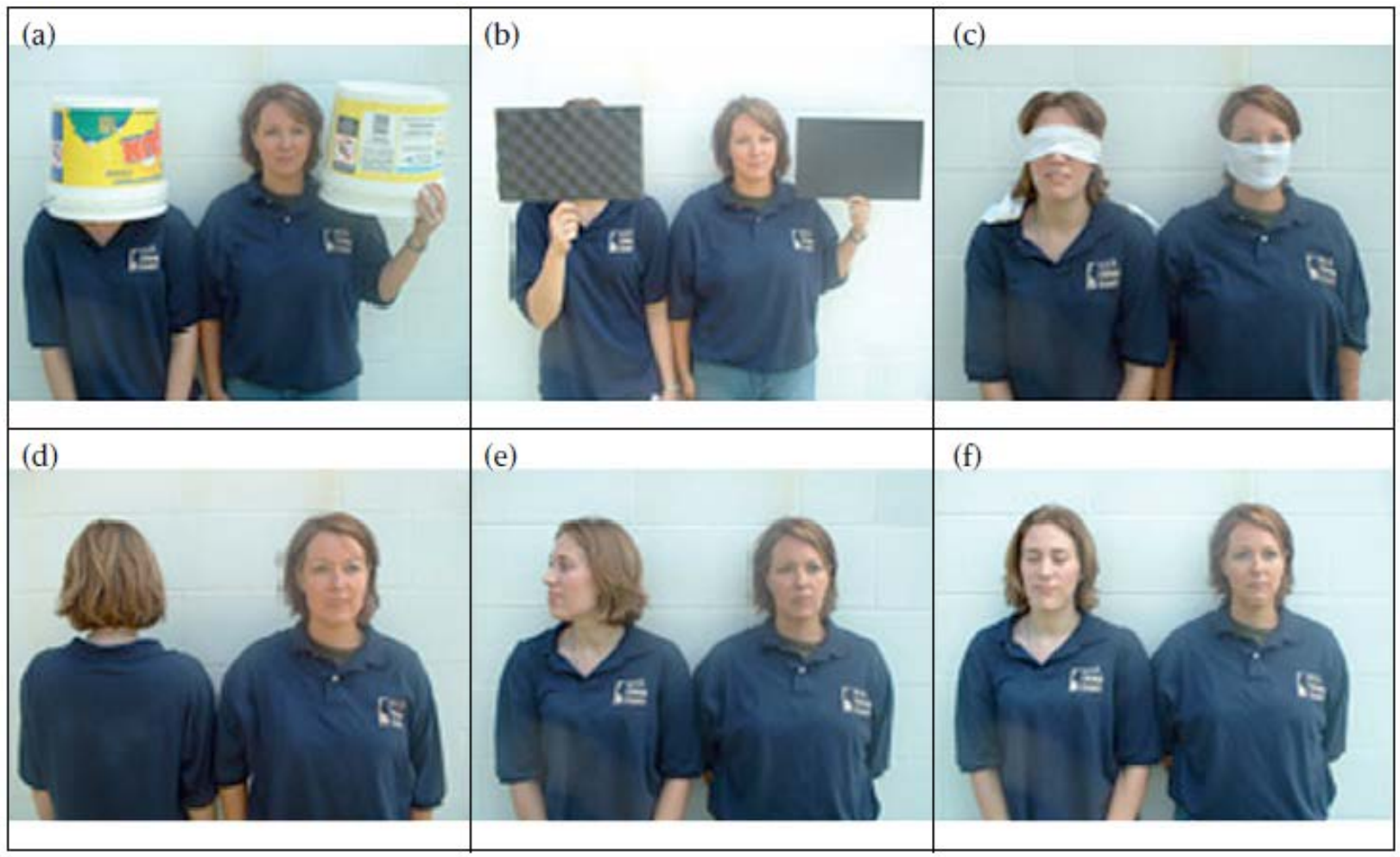

A research assistant informed the experimenters of the randomized condition for each trial and recorded all responses. At the beginning of each baseline trial, one experimenter emerged from behind a $2 \mathrm{~m}$ wooden blind and walked approximately $3 \mathrm{~m}$ to the plywood platform. The experimenter stood in front of the subject (on the right or left side of the platform) and looked directly ahead, while holding the food reward waist high. After the chimp gestured towards the experimenter, the experimenter provided the reward and walked back behind the blind.

For all experimental trials, both experimenters moved from behind the blind and walked to the testing platform simultaneously. Each experimenter took a position on the right or left side of the platform, during which they made no eye contact with the subject. The research assistant recorded the first gesture made towards one of the experimenters as the subject's 'choice' on data sheets and videotaped all trials. 
Criterion for subjects' success was the use of a hand gesture towards the 'seeing' experimenter. Because some of the animals had previously shown a preference for using their mouths or feet to indicate their choice, a hand gesture was required to maintain consistency of criterion across subjects. If the subject gestured ambiguously during a trial (i.e. pointing to both experimenters, using both hands), we repeated the trial at the end of the session ( 0 trials repeated during experiment 1 ). During testing, the research assistant observed from $3 \mathrm{~m}$ away, out of the animals' line of sight. On a given trial, either the laboratory assistant or 'seeing' experimenter indicated whether the chimpanzee subject's choice was correct. Because of the configuration of the test area, on a few occasions, the research assistant was unable to see as well as the 'seeing' experimenter. During those few trials, the 'seeing' experimenter indicated the subject's response, then gave the reward to the subject.

Figure 2. Performance of chimpanzees on each condition in experiment 1 as a percentage of correct responses over four trials.

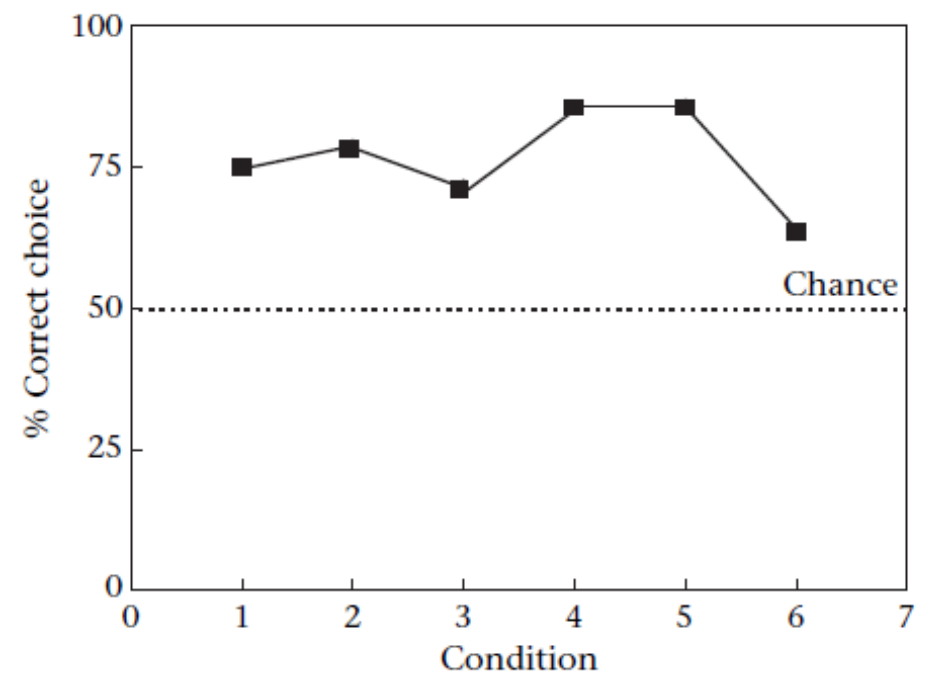

\section{Results}

Because we had four trials from each chimpanzee and must account for the dependence of our data, we transformed the raw data into a percentage score of correct responses. A repeated measures ANOVA revealed that the chimpanzees did not respond differently by condition $\left(F_{5,30}=1.1099, P=0.37\right.$; Fig. 2$)$. This finding suggests that the chimpanzees treated the six conditions equivalently. We then performed a series of post hoc $t$ tests against chance responding (held as 0.50). The subjects performed above chance on all conditions except condition 6 , in which the choice was between two experimenters, both facing forward, one with eyes open and the other with eyes closed (see Table 1).

When evaluated based on the 'face' and 'eye' rules proposed by Reaux et al. (1999), the Ohio State chimpanzees may have used both rules. When data from trial 1 of each condition were analysed, our subjects gestured towards the seeing experimenter at levels above chance on all conditions. They responded to the 'seeing' experimenter $100 \%$ of the time on the back/front condition (condition 4), $86 \%$ for both the bucket and screen conditions (conditions 1,2), $71 \%$ with the blindfold and eyes condition (condition 3), and $57 \%$ under the gaze away condition (condition 5). These results support our conclusion that the chimpanzees did not have to learn to discriminate the experimental conditions over repeated trials. Instead, they chose correctly from the first presentation (see Table 2). Inter-rater reliability was analysed by selecting a random set of 42 trials, representing approximately $10 \%$ of the total trials coded 
by a student assistant naïve to the experimental hypotheses. The reliability of compared observations was 95\% (kappa $=0.899, P=0.0001)$.

Table 1. Post hoc $t$ tests comparing chimpanzees' performance to chance responding for experiment 1

\begin{tabular}{|ccccccc|}
\hline & $\begin{array}{c}\text { Bucket } \\
\text { (condition 1) }\end{array}$ & $\begin{array}{c}\text { Screen } \\
\text { (condition 2) }\end{array}$ & $\begin{array}{c}\text { Blindfold } \\
\text { (condition 3) }\end{array}$ & $\begin{array}{c}\text { Back } \\
\text { (condition 4) }\end{array}$ & $\begin{array}{c}\text { Gaze away } \\
\text { (condition 5) }\end{array}$ & $\begin{array}{c}\text { Eyes } \\
\text { (condition 6) }\end{array}$ \\
\hline$t$ & 2.64 & 1.55 & 2.48 & 7.07 & 6.0 & 4.80 \\
$P$ & 0.02 & 0.14 & 0.03 & 0.00 & 0.00 & 0.00 \\
\hline
\end{tabular}

Table 2. Percentage of correct first trial responses by chimpanzees in experiment 1

\begin{tabular}{|lcccccc|}
\hline Chimpanzee & $\begin{array}{c}\text { Bucket } \\
\text { (condition 1) }\end{array}$ & $\begin{array}{c}\text { Screen } \\
\text { (condition 2) }\end{array}$ & $\begin{array}{c}\text { Blindfold } \\
\text { (condition 3) }\end{array}$ & $\begin{array}{c}\text { Back } \\
\text { (condition 4) }\end{array}$ & $\begin{array}{c}\text { Gaze away } \\
\text { (condition 5) }\end{array}$ & $\begin{array}{c}\text { Eyes } \\
\text { (condition 6) }\end{array}$ \\
\hline Darrell & $100 \%$ & $100 \%$ & $100 \%$ & $100 \%$ & 0 & $100 \%$ \\
Kermit & $100 \%$ & $100 \%$ & $100 \%$ & $100 \%$ & $100 \%$ & $100 \%$ \\
Bobby & 0 & 0 & $100 \%$ & $100 \%$ & $100 \%$ & $100 \%$ \\
Sheba & $100 \%$ & $100 \%$ & 0 & $100 \%$ & $100 \%$ & $100 \%$ \\
Sarah & $100 \%$ & $100 \%$ & 0 & $100 \%$ & $100 \%$ & 0 \\
Keeli & $100 \%$ & $100 \%$ & $100 \%$ & $100 \%$ & 0 & $100 \%$ \\
Ivy & $100 \%$ & $100 \%$ & $100 \%$ & $100 \%$ & 0 & 0 \\
Mean & $86 \%$ & $86 \%$ & $71 \%$ & $100 \%$ & $57 \%$ & $71 \%$ \\
\hline
\end{tabular}

\section{Discussion}

The results of the present experiment revealed that the Ohio State chimpanzees were able to discriminate between conditions in which experimenters could and could not see from the first presentation of each condition. The subjects' overall performance indicated that they chose the 'seeing' experimenter at statistically significant levels with minimal prior experience with the visual attention paradigm (12 baseline trials). These findings stand in sharp contrast to those reported by Povinelli \& Eddy (1996a, b) and Reaux et al. (1999). The New Iberia subjects did not perform significantly above chance on conditions during which the 'eye' rule could be used, despite many opportunities for training and testing with some form of visual attention task from age 5 until 8-9 years of age. Furthermore, the New Iberia subjects did not select consistently the correct experimenter until they were approximately 8 years old (Reaux et al. 1999). The animals' performance rose above chance for most conditions only when the visual attention task had been presented for training and testing twice, or 12 trials per condition for each animal. In addition, although the New Iberia subjects received the test conditions three times more often than did the Ohio State subjects, the New Iberia chimpanzees did not respond optimally to the eyes open/eyes closed condition (Reaux et al. 1999), suggesting that the New Iberia subjects did not readily acquire either the 'eye' rule or a more general understanding of the importance of visual attention.

\section{EXPERIMENT 2}

\section{Replication of Reaux et al.'s (1999) Experiment 3}

We performed experiment 2 to evaluate further the Ohio State chimpanzees' understanding of visual attention. We determined in experiment 1 that, minimally, our subjects were able to use both the face and eye rules (unlike the subjects in Reaux et al.'s 1999 study), and that further testing might clarify whether 
their performance was based on a capacity to discriminate the stimulus characteristics of the correct experimenter, or a more general understanding of the significance of visual attention. To address these questions, we replicated experiments 3 and 4 from Reaux et al. (1999). Note that Reaux et al.'s (1999) experiment 2 was a repetition of their experiment 1 because their animals had failed previously, so it was unnecessary for us to repeat their experiment 2 with our subjects. Therefore, we conducted more sophisticated experiments based on Reaux et al.'s (1999) experiments 3 and 4, which are referred to here, respectively, as experiments 2 and 3 .

Figure 3. Experimental conditions presented in experiment 2: (a) screen beside face, gaze away, (b) screen beside face, bucket over head and (c) blindfold over mouth/eyes closed, facing forward. The experimenter on the right side in each panel is demonstrating the 'seeing' conditions.

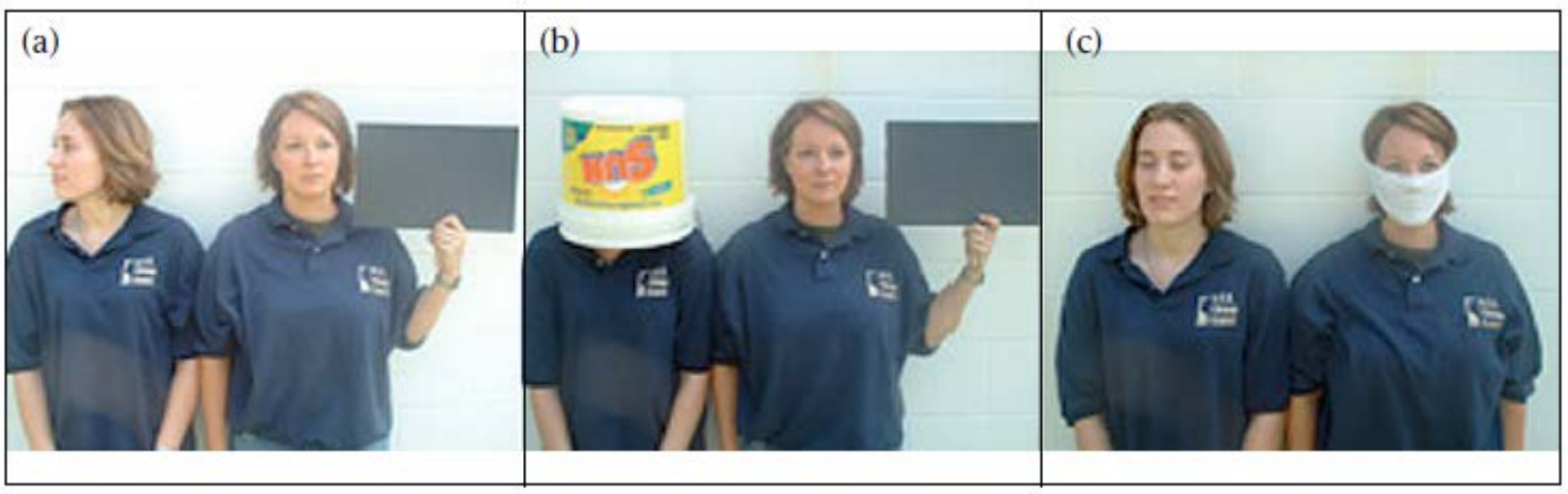

Figure 4. Performance of chimpanzees on each condition in experiment 2 as a percentage of correct responses over four trials.

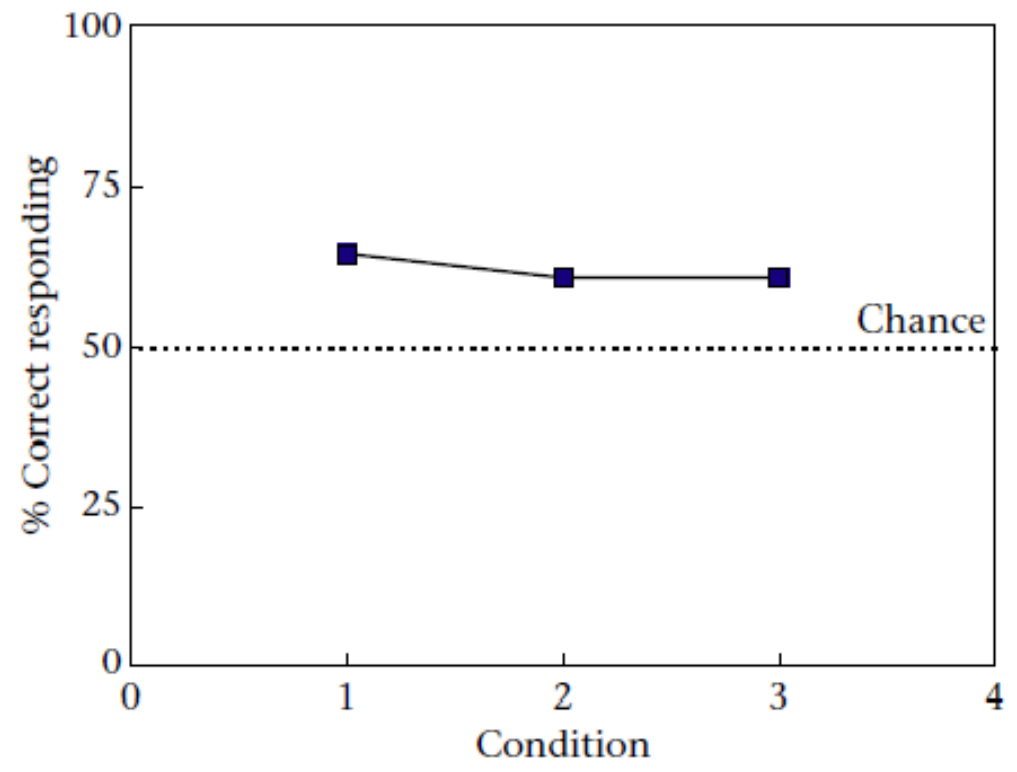

Table 3. Post hoc $t$ tests comparing chimpanzees' performance to chance responding for experiment 2

\begin{tabular}{|cccc|}
\hline & Condition 1 & Condition 2 & Condition 3 \\
\hline$t$ & 1.33 & 1.16 & 0.89 \\
$P$ & 0.21 & 0.26 & 0.39 \\
\hline
\end{tabular}




\section{Methods}

The methods for this experiment were identical to those of experiment 1 , and the same chimpanzees served as subjects. We presented test trials representing three different experimental conditions. These included: (1) screen beside face/gaze away (Fig. 3a); (2) screen beside face/bucket over head (Fig. 3b); (3) blindfold over mouth/eyes closed, facing forward (Fig. 3c). In Fig. 3, the individual on the right represents the 'seeing' condition and the individual on the left represents the 'not seeing' condition. Test trials were randomized across the three experimental conditions, such that the subjects received two sessions of six trials each composed solely of experimental trials. One trial for one subject (Keeli) was repeated because the subject's response was ambiguous.

\section{Results}

A repeated measures ANOVA revealed no evidence for differential performance on the three conditions by the chimpanzees $\left(F_{2,12}=0.039, P=0.096\right.$; Fig. 4). Not surprisingly, when the conditions were tested individually against chance through a series of $t$ tests, the results were not significantly different from chance (Table 3).

\section{Discussion}

In our replication of Reaux et al.'s (1999) experiment 3, the Ohio State chimpanzees did not successfully show their knowledge of visual attention. The pattern of results reported for the New Iberia chimpanzees revealed that, following significant training, subjects' responses were based on using a face rule, which suggests either that the face rule could not be applied flexibly, or that the subjects were unable to learn the eye rule required for correct responding under some experimental conditions (Reaux et al. 1999). Given the Ohio State chimpanzees' success in experiment 1, their failure in experiment 2 was surprising. Further evaluation of the data revealed that our results were largely driven by the (outlier) performance of one subject, Ivy. Moreover, all chimpanzees except Ivy performed above chance across all conditions. Analyses of the performance of the six remaining subjects, minus the outlier performance of Ivy, was $67 \%$ correct on both screen conditions and $70 \%$ correct on the blindfold over mouth/eyes closed/facing forward condition. When Ivy was removed from the sample, the resulting ANOVA $\left(F_{3,23}=13.0, P>0.00001\right)$ revealed that the chimpanzees performance was well above chance. Given the limited sample size $(N=$ 7 ), the effect of an anomalous score (Ivy) would have greater impact on the overall results. These findings are addressed further in the General Discussion.

\section{EXPERIMENT 3}

\section{Replication of Reaux et al.'s (1999) Experiment 4}

Given the results of experiments 1 and 2, we sought to determine the pattern of responding by the Ohio State chimpanzees in a replication of Reaux et al.'s (1999) experiment 4.

\section{Methods}

We compared the use of the face and eye rules using four combinations of experimental conditions with the same seven subjects. The methods in this study were identical to those of experiment 3 , with the exception of the experimental conditions. The four conditions were: (1) looking over shoulder vs twisting back, looking away; (2) eyes open, facing forward vs eyes closed, facing forward; (3) looking over shoulder vs eyes closed, facing forward; and (4) facing forward vs facing backward (Fig. 5). We presented the conditions over three sessions, with six trials in the first two sessions and four trials in the third 
session. One trial for one subject (Bobby) was repeated because the subject' s response was ambiguous.

\section{Results}

A repeated measures ANOVA revealed that chimpanzees responded to the four conditions differently $\left(F_{3,18}=14.58, P<0.00005\right.$; Fig. 6$)$. A series of $t$ tests against chance performance revealed that the subjects' performance was significantly above chance on conditions 1,2 and 4 . However, their performance was significantly incorrect in condition 3 (Table 4).

Figure 5. Experimental conditions, experiment 3: (a) looking over shoulder, eyes closed facing forward, (b) front/back, (c) looking over shoulder, looking away, and (d) eyes open, eyes closed. The experimenter on the right side in each panel is demonstrating the 'seeing' condition.

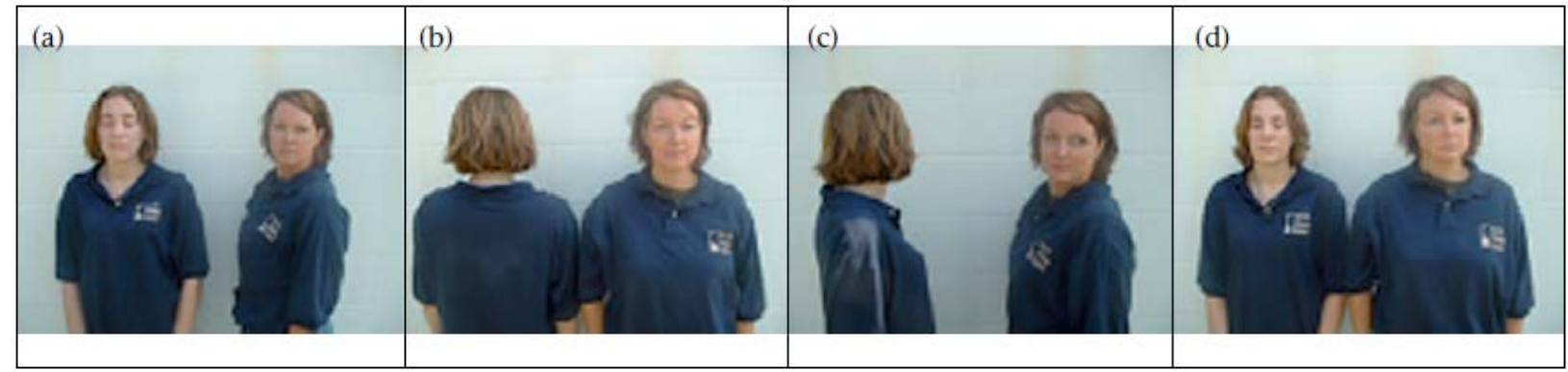

\section{Discussion}

As in experiment 1 , the animals' performance showed that they understood the impact of posture under conditions when the experimenter was facing forward versus facing backward, and also that they understood the 'eye' rule under the second experimental condition (eyes open, facing forward vs eyes closed, facing backward). They also were successful in selecting the seeing experimenter in the first condition (looking over shoulder vs twisting away, looking back). Thus, the animals were able to take into account the experimenter's posture relative to determining visual attention. Their performance on these three conditions also showed their ability to recognize the importance of eyes, posture and face for evaluating visual attention. However, in condition 3 (looking over shoulder vs eyes closed, facing forward), the chimpanzees chose the experimenter that was facing forward, even though the experimenter's eyes were closed.

These findings, in light of the animals' earlier performance, required further evaluation. Condition 3 was the only one that required comparing an experimenter posed in full frontal posture, but without visual access. Under other conditions, when a choice had to be made between an experimenter facing forward with her eyes closed, the second experimenter was also facing forward. Thus, these results suggested that the frontal posture was likely to be indicative of visual attention, given the physical placement of our eyes. Arguably, in social interactions with other chimpanzees, an individual chimpanzee viewing a conspecific may be more likely to pay attention to overall posture. Body posture and other concomitant changes in other features of the body, such as piloerection, muscle tension and speed of movement, can communicate important information to an observing chimpanzee in a social group. Indeed, the rapid apprehension of such physical features could conceivably have dramatic survival value if a chimpanzee encountered a displaying adult male, particularly a stranger. The rapid assessment of another individual's body form and other specific physical features would communicate to the observer the urgent need to move away as quickly and as far away as possible. Consequently, overall body posture and other discernible global features could immediately demand focus of attention. Chimpanzees' face and eyes, as 
features of their repertoire of facial expressions, also provide significant information about emotional state and intention, but probably would be secondary to posture under conditions of immediate danger.

Figure 6. Performance of chimpanzees on each condition in experiment 3 as a percentage of correct responses over four trials.

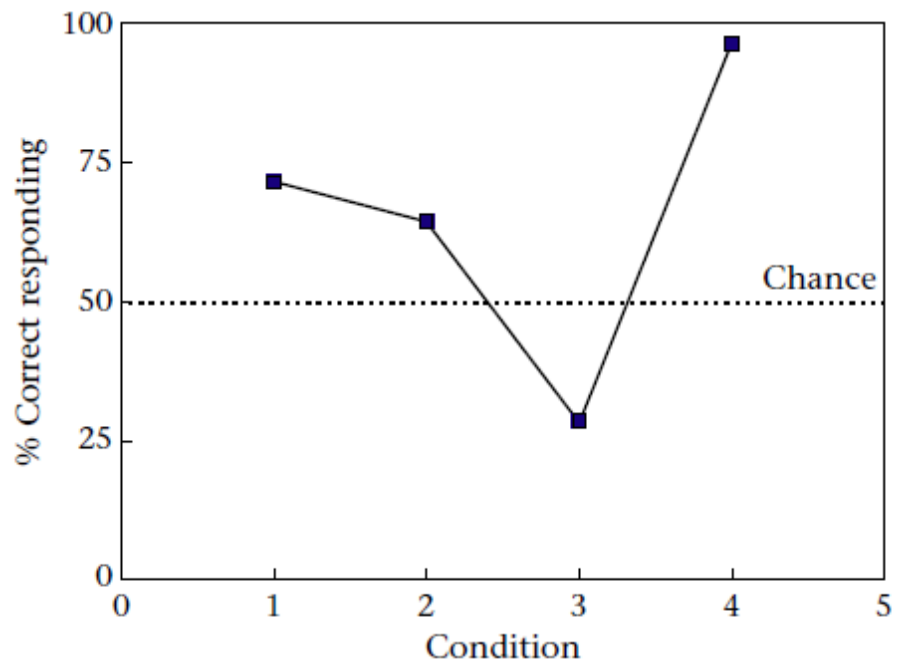

Table 4. Post hoc $t$ tests comparing chimpanzees' performance to chance responding for experiment 3

\begin{tabular}{|ccccc|}
\hline & $\begin{array}{c}\text { Look over shoulder } \\
\text { (condition 1) }\end{array}$ & $\begin{array}{c}\text { Open eyes } \\
\text { (condition 2) }\end{array}$ & $\begin{array}{c}\text { Look over shoulderleyes closed } \\
\text { (condition 3) }\end{array}$ & $\begin{array}{c}\text { Forward facing/back } \\
\text { (condition 4) }\end{array}$ \\
\hline$t$ & 3.28 & 2.87 & -2.12 & 13.0 \\
$P$ & 0.007 & 0.015 & 0.055 & 0.00 \\
\hline
\end{tabular}

In comparison, responses of the New Iberia animals in Reaux et al.'s experiment 4 revealed success with the back/front and looking over shoulder conditions. Their performance on the eyes open/eyes closed condition, however, did not differ significantly from chance; they were correct only $28 \%$ of the time when one experimenter was looking over her shoulder and the other experimenter was facing forward but with her eyes closed. This pattern of responding suggested that the New Iberia chimpanzees learned to use specific rules (eyes, face) acquired over many training trials and persisted in applying these acquired rules during subsequent tests of visual attention.

\section{GENERAL DISCUSSION}

The results of the present experiments offer strong evidence contrary to the claim that all chimpanzees follow a pattern of rule acquisition and state knowledge, as proposed by Reaux et al. (1999). The Ohio State subjects were able to perform successfully on tasks replicated from the report of Reaux et al. (1999), typically from trial 1 under most experimental conditions. They also readily generalized their understanding of the significance of visual attention from the first experimental trial (e.g. trial 1 performance in experiment 1), and further demonstrated such comprehension under more complex test conditions (e.g. our experiment 3). Indeed, some of the specific failures observed in our experiments 2 and 3 may provide the best demonstration of the Ohio State chimpanzees' intuitive understanding of visual attention. For example, the animals' difficulty with the experimental condition during which one experimenter was looking over her shoulder with her back towards the subject and the other experimenter 
was facing forward with her eyes closed was very informative. Based on the chimpanzees' responses, these data suggest that the animals had difficulty inhibiting their choice of an experimenter with a frontal posture, compared to someone looking over their shoulder, regardless of eye condition. Interestingly, when we look at the poor performance of chimpanzees in experiment 2, particularly Sheba and Ivy, all conditions of this experiment involved the same forward facing posture with an apparatus to occlude the experimenter eyes. This may represent something closer to chance performance with frontal posture, a default response, interfering with use of the eye rule. In contrast, it appears that the New Iberia chimpanzees adhered rigidly to a 'face' rule related to frontal posture, and eventually incorporated a second strategy, based on the status of the eyes (the 'eye' rule). Consequently, the constellation of responses shown by their subjects is best explained by these two associative rules.

Why did the performance of The Ohio State University chimpanzees differ so dramatically from that of chimpanzees in previous studies using the same testing conditions (Reaux et al. 1999; Povinelli 2000)? First, the social milieu of the Ohio State group was a highly enriched, enculturated environment with daily social interactions with humans and mixed-age conspecifics that had long-term stable relationships with the subjects, in a physical environment that allowed for and facilitated hypothesis testing about objects and actions. The animals also experienced outcomes that mimicked many facets of a wild chimpanzee's natural environment, as well as providing an enhanced context for cognitive development (Furlong et al. 2008). The opportunities afforded by such an enculturated upbringing probably enhanced the ability of the Ohio State chimpanzees to understand visual attention and to pay attention to the actions of their human companions. Although there have been some studies pointing to a contributing role for enculturation in chimpanzee cognitive development (e.g. see Tomasello et al. 1996; Visalberghi et al. 1995; Call \& Tomasello 1996), at this time it is not possible to tease apart the differential contributions of enrichment, human-chimpanzee social interactions, mixed-age conspecifics and physical challenges on our subjects' successful performance. What can be said conclusively is that the Ohio State chimpanzees outperformed the New Iberia chimps on tasks requiring an understanding of visual attention.

In summary, it was our intention to replicate the methods and procedures of Reaux et al. (1999) as closely as possible from their descriptions in order to evaluate their conclusion that chimpanzees are not capable of recognizing the import of visual attention beyond the acquisition of perceptually based rules. However, given the substantive evidence presented here and results from numerous additional studies (e.g. Tomasello et al. 1998, 1999, 2007; Kaminski et al. 2004; Bräuer et al. 2005; Hostetter et al. 2007), a widespread claim that all chimpanzees are unable to comprehend the role of visual attention is patently untrue. While the pattern of results from the Ohio State subjects suggests that, indeed, representation of visual attention in chimpanzees may not be identical to that shown by humans, their performance in our experiments indicates a readily available understanding of the power and import of visual access that may become accessible under certain conditions, including potential contributions of enculturation and other related experiences (Call \& Tomasello 1996; Whiten et al. 1999; Hostetter et al. 2007; Furlong et al. 2008). These findings clearly show that enculturated chimpanzees can use visual attention to direct preferential gesturing towards individuals based upon an emergent understanding of visual attention beyond the application of simpler, perceptually based associative rules. Further studies will be necessary to tease apart the contributions of social referencing, issues related to reciprocal interpretations of intentionality, understanding of folk physics, perspective-taking and other critical social and environmental features that characterize the emerging caregiver-infant dyad in human culture, and the comparable impact of an analogous, long-term, enculturated environment for captive chimpanzees.

\section{Acknowledgments}

We acknowledge the unparalleled contributions of our dear friends, Darrell, his life-long companion Kermit, and Bobby, all three of whom left us with fond memories of their remarkable capacities and 
generous souls. They are sorely missed. Equally significant contributions were made by our remaining chimpanzees, Sarah, Sheba, Keeli, Ivy, Emma and Harper. We also appreciate their dedicated teachers, Klaree Boose and Stephany Harris, and the many students and community volunteers, without whose help these studies would have been impossible to conduct. Comments on the manuscript from Robert Seyfarth, an anonymous referee, and the Editor are also gratefully acknowledged.

\section{References}

Boysen, S. T. 2006. The impact of symbolic representation chimpanzee cognition. In: Rational Animals (Ed. by S. I. Hurley \& M. Nudds), pp. 489-511. Oxford: Oxford University Press.

Bräuer, J., Call, J. \& Tomasello, M. 2005. All great ape species follow gaze to distant locations and around barriers. Journal of Comparative Psychology, 119, 145-154.

Call, J. \& Tomasello, M. 1996. The effect of humans on the cognitive development of apes. In: Reaching into Thought (Ed. by A. E. Russon, K. A. Bard \& S. T. Parker), pp. 371-403. Cambridge: Cambridge University Press.

Furlong, E. E., Boose, K. J. \& Boysen, S. T. 2008. Raking it in: the impact of enculturation on chimpanzees' tool use. Animal Cognition, 11, 83-97.

Hare, B., Call, J., Agnetta, B. \& Tomasello, M. 2000. Chimpanzees know what conspecifics do and do not see. Animal Behaviour, 59, 771-785.

Hare, B., Call, J. \& Tomasello, M. 2001. Do chimpanzees know what conspecifics know? Animal Behaviour, 61, 139-151.

Hostetter, A. B., Russell, J. L., Freeman, H. \& Hopkins,W. D. 2007. Now you see me, now you don't: evidence that chimpanzees understand the role of eyes in attention. Animal Cognition, 10, 55-62.

Kaminski, J., Call, J. \& Tomasello, M. 2004. Body orientation and face orientation: two factors controlling apes' begging behavior from humans. Animal Cognition, 7, 216-223.

Kuhlmeier, V. A. \& Boysen, S. T. 2001. The effect of response contingencies on scale model task performance by chimpanzees (Pan troglodytes). Journal of Comparative Psychology, 115, 300306.

Kuhlmeier, V. A. \& Boysen, S. T. 2002. Chimpanzees (Pan troglodytes) recognize spatial-and-object correspondences between a scale model and its referent. Psychological Science, 13 (1), 60-63.

Kuhlmeier, V. A., Boysen, S. T. \& Mukobi, K. L. 1999. Scale-model comprehension by chimpanzees (Pan troglodytes). Journal of Comparative Psychology, 113, 396-402.

Leavens, D. \& Hopkins, W. 1998. Intentional communication by chimpanzees: a cross-sectional study of the use of referential gestures. Developmental Psychology, 34, 813-822.

Leavens, D., Hopkins, W. \& Bard, K. A. 1996. Indexical and referential pointing in chimpanzees (Pan troglodytes). Journal of Comparative Psychology, 110, 346-353.

Povinelli, D. J. 2000. Folk Physics for Apes: the Chimpanzee's Theory of How the World Works. Oxford: Oxford University Press.

Povinelli, D. J. \& Eddy, T. J. 1996a. What young chimpanzees know about seeing. Monographs of the Society for Research in Child Development, 61, 1-152.

Povinelli, D. J. \& Eddy, T. J. 1996b. Factors influencing young chimpanzees' (Pan troglodytes) recognition of attention. Journal of Comparative Psychology, 110, 336-345.

Povinelli, D. J. \& Vonk, J. 2003. Chimpanzee minds: suspiciously human? Trends in Cognitive Sciences, 7, 157-160.

Povinelli, D. J. \& Vonk, J. 2004. We don't need a microscope to explore the chimpanzee's mind. Mind \& Language, 19, 1-28.

Povinelli, D. J., Bierschwale, D. T. \& Cech, C. G. 1999. Comprehension of seeing as a referential act in young children but not juvenile chimpanzees. British Journal of Developmental Psychology, 17, 37-60. 
Povinelli, D. J., Dunphy-Lelii, S., Reaux, J. E. \& Mazza, M. 2002. Psychological diversity in chimpanzees and humans: new longitudinal assessments of chimpanzees' understanding of attention. Brain, Behavior \& Evolution, 59, 33-53.

Premack, D. \& Woodruff, G. 1978. Does the chimpanzee have a theory of mind? Behavioral and Brain Sciences, 1, 515-526.

Reaux, J. E., Theall, L. A. \& Povinelli, D. J. 1999. A longitudinal investigation of chimpanzees' understanding of visual perception. Child Development, 70, 275-290.

Santos, L. \& Hauser, M. D. 1999. How monkeys see the eyes: cotton-top tamarins' reaction to changes in visual attention and action. Animal Cognition, 2, 131-139.

Santos, L., Nissen, A. G. \& Ferrugia, J. A. 2006. Rhesus monkeys, (Macaca mullata), know what others can and cannot hear. Animal Behaviour, 71, 1175-1181.

Tomasello, M. 2000. Uniquely primate, uniquely human. Developmental Science, 1, 1-30.

Tomasello, M., Call, J. \& Hare, B. 1998. Five primate species follow gaze direction geometrically. Animal Behaviour, 55, 1063-1069.

Tomasello, M., Hare, B. \& Agnetta, B. 1999. Chimpanzees (Pan troglodytes) follow gaze direction geometrically. Animal Behaviour, 58, 769-777.

Tomasello, M., Hare, B. \& Fogleman, T. 2001. The ontogeny of gaze following in chimpanzees (Pan troglodytes) and rhesus macaques (Macaca mulatta). Animal Behaviour, 61, 335-343.

Tomasello, M., Call, J. \& Hare, B. 2003. Chimpanzees understand psychological states: the question is which ones and to what extent. Trends in Cognitive Sciences, 7, 153-156.

Tomasello, J., Hare, B., Lehman, H. \& Call, J. 2007. Reliance on head versus eyes in the gaze following of great apes and human infants: the cooperative eye hypothesis. Journal of Human Evolution, 52, 314-320.

Visalberghi, E., Fragaszy, D. M. \& Savage-Rumbaugh, E. S. 1995. Performance in a tool-using task by common chimpanzees (Pan troglodytes), bonobos (Pan paniscus), an orangutan (Pongo pygmaeus), and capuchin monkeys (Cebus apella). Journal of Comparative Psychology, 109, 5260.

Whiten, A., Goodall, J., McGrew, W. C., Nishida, T., Reynolds, V., Sugiyama, Y., Tutin, C. E. G., Wrangham, R. W. \& Boesch, C. 1999. Cultures in chimpanzees. Nature, 399, 682-685. 